\title{
Otolith microchemistry and diadromy in Patagonian river fishes
}

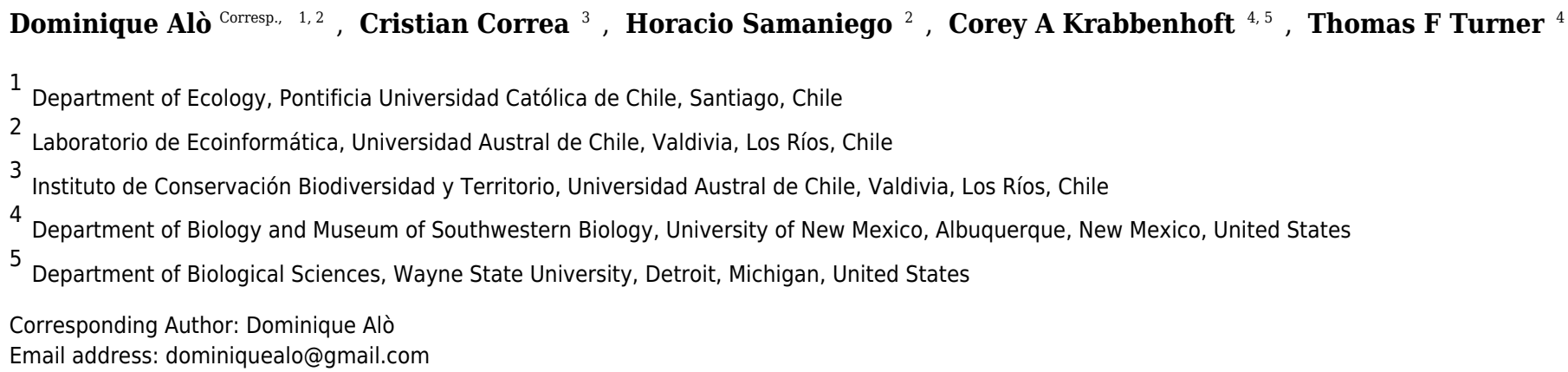

Coastal habitats in Chile are hypothesized to support a number of diadromous fish species. The objective of this study was to document migratory life histories of native galaxiids and introduced salmonids from a wide latitudinal range in Chilean Patagonia (39-48 $\mathrm{S}$ ). Otolith microchemistry data were analysed using a recursive partitioning approach to test for diadromy. Based on annular analysis of Sr:Ca ratios, a diadromous life history was suggested for populations of native Aplochiton taeniatus, A. marinus, and Galaxias maculatus. Lifetime residency in freshwater was suggested for populations of $A$. zebra and G. platei. Among introduced salmonids, populations of Oncorhynchus tshawytscha and $O$. kisutch exhibited patterns consistent with anadromy, whereas the screened population of O. mykiss appeared restricted to freshwater. Salmo trutta exhibited variable patterns suggesting freshwater residency and possibly anadromy in one case. The capacity and geographic scope of hydropower development is increasing and may disrupt migratory routes of diadromous fishes. Identification of diadromous species is a critical first step for preventing their loss due to hydropower development. 


\section{Otolith microchemistry and diadromy in Patagonian river fishes}

2

3 Authors: Dominique Alò ${ }^{1,2}$, Cristian Correa $^{3}$, Horacio Samaniego ${ }^{2}$, Corey A. Krabbenhoft ${ }^{4,5}$,

4 Thomas F. Turner ${ }^{4}$

5

6 1Departamento de Ecología, Pontificia Universidad Católica de Chile, Santiago, Chile

7 2Laboratorio de Ecoinformática, Universidad Austral de Chile, Valdivia, Los Ríos, Chile

8 Instituto de Conservación Biodiversidad y Territorio, Universidad Austral de Chile, Valdivia,

9 Los Ríos, Chile

$10{ }^{4}$ Department of Biology and Museum of Southwestern Biology, University of New Mexico,

11 Albuquerque, New Mexico, U.S.A

$12{ }^{5}$ present address: Department of Biological Sciences, Wayne State University, Detroit, Michigan, 13 U.S.A.

\section{Corresponding Author:}

16 Dominique Alò

17

18 Email address: dominiquealo@gmail.com

19 


\section{Abstract}

22 Coastal habitats in Chile are hypothesized to support a number of diadromous fish species. The

23 objective of this study was to document migratory life histories of native galaxiids and

24 introduced salmonids from a wide latitudinal range in Chilean Patagonia $\left(39-48^{\circ} \mathrm{S}\right)$. Otolith

25 microchemistry data were analysed using a recursive partitioning approach to test for diadromy.

26 Based on annular analysis of Sr:Ca ratios, a diadromous life history was suggested for

27 populations of native Aplochiton taeniatus, A. marinus, and Galaxias maculatus. Lifetime

28 residency in freshwater was suggested for populations of A. zebra and G. platei. Among

29 introduced salmonids, populations of Oncorhynchus tshawytscha and O. kisutch exhibited

30 patterns consistent with anadromy, whereas the screened population of $O$. mykiss appeared

31 restricted to freshwater. Salmo trutta exhibited variable patterns suggesting freshwater residency

32 and possibly anadromy in one case. The capacity and geographic scope of hydropower

33 development is increasing and may disrupt migratory routes of diadromous fishes. Identification

34 of diadromous species is a critical first step for preventing their loss due to hydropower

35 development. 


\section{Introduction}

Only 47 native and 27 non-native inland fish species are currently recognized in Chile, and several of these are thought to exhibit some tolerance for shifting between saline and

40 freshwater habitats (Dyer, 2000; Habit \& Victoriano, 2005; Habit, Dyer \& Vila, 2006; Vila et al.,

41 2011; Ministerio del Medio Ambiente, 2013; Vargas, Arismendi \& Gomez-Uchida, 2015).

42 Approximately $15 \%$ of these fishes are hypothesized to display diadromous migratory behaviour 43 (Table S1), compared to less than 1\% for fishes worldwide (Nelson, 2006).

The term diadromy describes regular, predictable, and physiologically mediated

movements between freshwater and the sea. Diadromy necessitates profound physiological changes (i.e., osmoregulation) when shifting from marine to freshwater habitats and vice versa (Gross, Coleman \& McDowall, 1988). Diadromy can be either obligatory or facultative (Dingle $\&$ Drake, 2007). The direction of migration depends on life history stages and habitats where reproductive and feeding events occur. The combination of these factors defines three different types of diadromy: anadromy, catadromy, and amphidromy (Myers, 1949; Gross, 1987; Gross, Coleman \& McDowall, 1988; McDowall, 1992, 1997; Limburg et al., 2001) (in particular refer to McDowall 1997 for a review of the terminology and a visual aid).

Given the high percentage of fishes in Chile hypothesized to exhibit some form of diadromy, migration might play an important, yet unrecognized role in establishing national priorities of aquatic biodiversity conservation. At present, a high percentage of the continental ichthyofauna in Chile is categorized with some degree of conservation threat by Chilean environmental agencies and other authors, although conservation categories can be incongruent and threats underestimated (Habit \& Victoriano, 2005; Diario Oficial de la Republica de Chile, 2008; Ministerio del Medio Ambiente, 2013; IUCN, 2015; Vargas, 
Arismendi \& Gomez-Uchida, 2015).

Coastal habitats in Chile appear well suited to support establishment of diadromous species. Andean rivers that flow into the Pacific Ocean include a variety of different habitats in a limited longitudinal distance (average $145 \mathrm{~km}$ ), spanning from areas of rocky substrates, high elevation gradients, clear waters and low temperatures, to areas of low flow, sandy substrates, and aquatic vegetation (Habit \& Victoriano, 2005; Instituto Nacional de Estadisticas, 2015). Spatial habitat heterogeneity is essential for maintenance and completion of diadromous life cycles, and for maintaining evolutionary potential (i.e., genetic diversity) for life history variation (Pulido, 2007; Dingle, 2014). Therefore, fragmentation events imposed by humanmade barriers may affect fish fitness and restrict movement between habitats more so than in other areas (Waples et al., 2007).

Patagonian fishes offer a unique opportunity to understand migration patterns in relatively pristine habitats and establish a baseline against which future potential impacts associated with river impoundments can be compared. Despite strong economic growth and efforts to develop hydroelectric potential to meet the country's growing energetic demand (Joo, Kim \& Yoo, 2015), many rivers in southern Chile are still free-flowing, offering opportunities to study pre-impoundment patterns of diadromous migration. In particular, galaxiid fishes are distributed across the temperate Southern Hemisphere (McDowall, 2002b) and diadromy seems to be a recurrent trait among many of the species (McDowall, 1971, 1988). Likewise, salmonids are among some of the best studied diadromous fishes in the Northern Hemisphere and are now well established in southern Chile (McDowall, 2002a; Correa \& Gross, 2008).

Using micro-geochemical data obtained from otoliths, this study sought to investigate whether native galaxiids and introduced salmonids exhibit diadromy in Chilean rivers. Otoliths 
83 are calcified deposits in the inner ear of fishes that accumulate in ring-like fashion over

84 ontogenetic growth. Elemental analysis of otoliths can help to distinguish origins of marine and

85 freshwater fishes among locations with variable water chemistry. Differing chemical

86 composition of the otolith from the primordium (core) to the edge is indicative of the different

87 environments in which a fish has lived and allows for hypothesis tests related to patterns of fish

88 movement. When analysed sequentially across an otolith sagittal section, changes in elemental

89 ratios can inform fine-scale patterns of movement, connectivity, dispersal, and the location of

90 natal habitats (Halden et al., 2000; Howland et al., 2001; Kraus, 2004; Ashford et al., 2005;

91 Campana, 2005; Arkhipkin, Schuchert \& Danyushevsky, 2009). To quantify these changes in

92 Patagonian fishes, we applied univariate recursive partitioning approaches based on

93 Classification and Regression Trees (CART) to detect discontinuities in elemental ratios that

94 may indicate habitat shifts (Vignon, 2015).

95 This research was motivated by the necessity to understand the potential for movement in

96 native and exotic fishes in non-impounded systems in southern Chile and used an existing

97 sample pool (Correa \& Hendry, 2012a,b; Correa, Bravo \& Hendry, 2012; Alò et al., 2013).

98 Several native fishes have previously been hypothesised to exhibit capacity for shifting between

99 marine and freshwater habitats (Dyer, 2000; Habit \& Victoriano, 2005; Habit, Dyer \& Vila,

100 2006; Vila et al., 2011; Ministerio del Medio Ambiente, 2013; Górski et al., 2015; Vargas,

101 Arismendi \& Gomez-Uchida, 2015) and some exotic salmonids appear to have established

102 successful diadromous life-histories (Ciancio et al., 2005, 2008; Riva-Rossi et al., 2007; Correa

103 \& Gross, 2008; Arismendi \& Soto, 2012; Araya et al., 2014; Górski et al., 2016). This study

104 sought to characterize the potential diadromous characteristics from a wider diversity of native

105 and exotic fish species in Patagonia, including previously unevaluated species sampled from a 
106 wider and unexplored geographic range. Inclusion of native and exotic species in this study

107 provided a framework to compare well-known life-history characteristics of northern hemisphere

108 salmonids to the lesser-known galaxiids.

109

110 Methods

\section{Fish Collections}

112 Between 2004 and 2011, specimens of Aplochiton zebra, A. taeniatus, A. marinus,

113 Galaxias maculatus, G. platei, Oncorynchus tshawytscha, O. kisutch, O. mykiss, and Salmo

114 trutta were collected using various methods from six locations across a large latitudinal range

115 (39.5-48.0 $\mathrm{S})$ in western Patagonia, Chile (Fig. 1, Table 1). At each location, fish specimens

116 were euthanized by an overdose of anaesthetic solution (tricaine-methanesulfonate MS-222 or

117 clove oil). Due to the difficulties in morphological identification, genetic data were used to

118 identify individuals in the genus Aplochiton to the species level (Alò et al., 2013). The McGill

119 University Animal Care Committee (UACC), Animal Use Protocol No. 5291, approved use and 120 handling of animals.

\section{Otolith preparation}

This study used the Strontium (Sr) to Calcium (Ca) molar ratio to infer habitat shifts

124 across salinity gradients of Patagonian fishes. Strontium is particularly useful for reconstructing

125 environmental history of fishes as it replaces $\mathrm{Ca}$ in the otolith matrix according to its availability

126 in the fish habitat (Secor \& Rooker, 2000; Campana, 2005; Pracheil et al., 2014).

127 Prior to specimen preservation, sagittal otoliths were extracted and either stored dry in

128 test tubes or in $95 \%$ ethanol, as elemental compositions and structures of otoliths are not strongly

129 affected by ethanol for the elements assayed (Proctor \& Thresher, 1998). In the laboratory, 
130 otoliths were polished, cleaned, and mounted individually on clean glass slides using a

131 thermoplastic cement (Crystalbond ${ }^{\mathrm{TM}}$ ). In order to expose growth rings, $3 \mathrm{M}^{\mathrm{TM}}$ (fine) and

132 Nanolap ${ }^{\circledR}$ Technologies (coarse) diamond lapping film wetted with deionized water was used to

133 polish otoliths by hand until a satisfactory sagittal section of annuli was visible (Fowler et al.,

134 1995). For Aplochiton spp., Galaxias spp., S. trutta, O. kisutch and O. mykiss otoliths, a 30- $\mu \mathrm{m}$

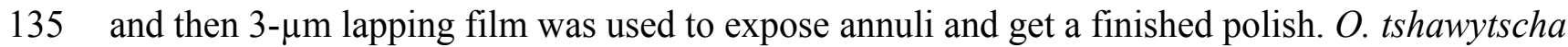

136 otoliths required larger lapping film $(45$ and $60 \mu \mathrm{m})$ to reach an appropriate view, but were

137 finished with $3 \mu \mathrm{m}$ film for increased clarity. For larger otoliths (e.g., O. tshawytscha), it was

138 sometimes necessary to polish on opposite sides to produce a thinner section.

139 Following polishing, the mounting adhesive was dissolved in a $100 \%$ acetone bath and

140 sonicated for 10 minutes. Larger otoliths were cleaned a second time with acetone as needed.

141 Each otolith was then sonicated twice in Milli-Q water for 5 to 10 minutes each. Following

142 cleaning, otoliths were rinsed a final time in Milli-Q water, transferred to clean vials and placed

143 in a positive laminar flow hood for 24-48 hours to dry (similar to methods of Elsdon \&

144 Gillanders, 2002).

145 Acid-washed porcelain forceps were used to mount clean, dry otoliths on acid-washed

146 microscope slides. Otoliths were grouped according to diameter and mounted 10-28 per slide

147 accordingly. Each otolith was placed within one small drop of fresh Crystalbond melted onto a 148 single slide.

149 Slides were securely kept in acid-washed, sealed petri dishes for transport to Woods Hole

150 Oceanographic Institute (Woods Hole, MA, U.S.A.). There, Laser ablation-inductively coupled

151 plasma-mass spectrometry (LA-ICP-MS) was conducted from October $8^{\text {th }}$ to $11^{\text {th }}, 2012$

152 (Aplochiton spp., S. trutta, Galaxias spp., O. kisutch, and O. mykiss) and again from February $4^{\text {th }}$ 
153 to $5^{\text {th }}, 2013$ (O. tshawytscha). Laser ablation was performed with a large format laser ablation

154 cell on a New Wave UP193 (Electro Scientific Industries, Portland, Oregon) short pulse width

155 excimer laser ablation system. This was coupled with a Thermo Finnigan Element2 sector field

156 argon plasma spectrometer (Thermo Electron Corporation, Bremen, Germany) for elemental

157 analysis. The laser was configured for single pass, straight line scanning at a speed of $5 \mu \mathrm{m}$ per

158 second. The laser beam spot size was $50 \mu \mathrm{m}$ at $75 \%$ intensity and $10 \mathrm{~Hz}$ pulse rate. Isotopic

159 activity rates (counts per second) were determined for ${ }^{87} \mathrm{Sr}$ and ${ }^{47} \mathrm{Ca}$. Certified standard FEBS-1

160 (Sturgeon et al., 2005) and a 1\% nitric acid $\left(\mathrm{HNO}_{3}\right)$ blank were passed through the instrument

161 before and after each block of 4 to 11 otoliths to minimize bias in elemental mass. Each otolith

162 was visualized on screen and the intended ablation transect of each sample was plotted digitally

163 and analysed by ablation with a laser beam (refer to Fig. 2 or supplemental pictures:

164 https://figshare.com/s/9855cff84b6b085f1b34 for a visual example).

165

166

\section{Data Analysis}

Digital images of each otolith were taken after the laser ablation procedure with a digital

Nikon Coolpix P6000 split with a Martin microscope MM Cool mounted on Nikon SMZ800

lenses and illuminated with a NII-LED High Intensity Illuminator (Supplemental pictures:

170 https://figshare.com/s/9855cff84b6b085f1b34).

171 For accuracy, each raw data point was produced from an average of ten consecutive

172 reads. Isotopic intensities were corrected subtracting the means of the isotopic intensities

173 detected in the blanks. Points below the limit of detection of the same isotope measured in the

174 blanks (mean - 3SD) were eliminated. Isotopic intensities were converted to elemental intensities

175 by taking into account the percent natural occurrence of the isotopes. Strontium was standardized 
176 to $\mathrm{Ca}$ and converted to molar Sr:Ca ratios using sequentially the measurements of the standard

177 reference material, and the atomic mass of the elements analysed (Wells et al., 2003; Wolff,

178 Johnson \& Landress, 2013) (Raw data and Python scripts to convert from isotopic intensities to

179 molar ratios provided as supplemental files Dataset S1). Elemental data and otolith transects

180 were rigorously checked, and outliers caused by recording errors were removed (additive

181 outliers, R Package "tsoutliers" v: 0.6-5, L'opez-de-Lacalle 2016). The ideal double life-history

182 transect obtained ran across each sagittal otolith and through the primordium, thus providing two

183 similar (redundant) patterns related to life history variation, one on either side of the primordium.

184 Interpretations were based on the analyses of both sides of each double transect, if possible.

185 However, in a number of cases, transects were imperfect due to damaged otoliths or inaccurate

186 ablation pathways (Supplemental pictures: https:/figshare.com/s/9855cff84b6b085f1b34). In

187 these cases, data were analysed as partial transects that were used to differentiate putatively

188 diadromous or resident signals (Fig. 2).

189 Classification and Regression Trees (CART, Breiman et al. 1984) were used to detect

190 shifts in elemental ratios across the otolith transect. CART is an alternative to qualitative

191 methods traditionally used to interpret the chronological signal in otolith microchemistry

192 transects (Vignon, 2015). The position along the otolith transect (predictor variable) was

193 recursively partitioned using regression trees in order to differentiate segments of the transect

194 that shared similar mean Sr:Ca values (response variables) (Breiman et al., 1984; Therneau \&

195 Atkinson, 1997; De'ath, 2002; Strobl, 2009). CART was implemented in the Tampo library

196 (version 1.0) for R Statistical Software 3.0.2 (Vignon, 2015).

197 Summary statistics of molar Sr:Ca ratios were calculated across all individuals. The main

198 goal of this work was to represent movement patterns at a broad scale. Therefore, since shifts in 
199 Sr:Ca have been well documented in many species of fish moving across environments with

200 variable Sr (Tzeng \& Tsai, 1994; Limburg, 1995; Tzeng, Severin \& Wickstrom, 1997; Campana,

201 1999; Limburg et al., 2001; Chang, Iizuka \& Tzeng, 2004; Araya et al., 2014), CART analysis

202 was used in a semi-supervised manner to identify the presence or absence of sudden

203 discontinuities in the Sr:Ca otolith signal (Vignon, 2015). This was done by setting three

204 progressively relaxed conditions to the splitting procedure. A splitting condition is the minimum

205 difference in mean values between consecutive Sr:Ca profile segments beyond which the

206 segments are permanently split in different categories. The three splitting conditions adopted

207 were $0.5,0.7$, and 1.0. The detection of one or more discontinuities or splits in the Sr:Ca signal

208 was interpreted as evidence in favour of diadromy, or otherwise, evidence in favour of residency.

209 When diadromy was inferred, the direction of ontogenetic movements was deduced from

210 differences in segment means; increasing values indicated movements towards the sea, and vice

211 versa.

212 Further inference about habitat occupancy (freshwaters, estuaries, or the sea) required a visual,

213 heuristic examination of Sr:Ca profiles in relation to i) the sites of capture, ii) comparisons with

214 movement patterns inferred from all the species analysed, iii) assumption of positive correlation

215 between environmental Sr and marine influence (Secor \& Rooker, 2000). Finally, all evidence

216 was assembled to make individual inferences about migration patterns suggestive of

217 amphidromy, catadromy, or anadromy. However, determining the precise extent of movements

218 between habitats was beyond the scope of this work. Finally, otolith transect quality affected the

219 confidence of our interpretations; from maximum confidence on inferences from transects that

220 conformed to the hypotheses of the models proposed in Fig. 2, to uncertain interpretations from

221 incomplete or faulty transects. 
223

224

225

226

227

228

229

230

231

232

233 Native galaxiids.

234

235

236

237

238

239

240

241

242

243

244

\section{Results}

\section{Native galaxilds.} no such shifts.

Observed variation in Sr:Ca ratios (Fig. 3) reflected a wide gradient of average values (lowest mean (sd) $0.66(+/-0.088)$ in G. platei and highest mean $4.03(+/-1.54)$ in G. maculatus). Depending on the species or population analysed, CART identified patterns of change in $\mathrm{Sr}: \mathrm{Ca}$ elemental ratios consistent with different migratory life histories proposed in the schematic representation in Fig. 2. Representative individuals for each species are shown in Fig. 4. Details on the splitting results of all individuals under different stringency conditions are given in Fig. 5 whereas Table S2 reports details on the mean and standard deviation at each split. A summary of the inferred migratory strategy for each species is shown in Table 1.

Large elemental shifts in otolith profiles suggested a catadromous life-history for most $A$. taeniatus analysed (Table 1 and Fig. 5). Even when confined to strictly freshwater habitats, as in Lake Caro, A. taeniatus juveniles showed a mild shift in Sr:Ca suggesting movements between freshwater habitats (Fig. 5, cond.=0.5), as contrasted with A. zebra or O. mykiss, which showed

Otolith profiles (Fig. 4 and 5) suggested that A. marinus copes with high levels of salinity variation in the Baker River system. Otolith primordia of all specimens of $A$. marinus showed evidence of higher Sr:Ca ratios at early stages of growth, presumably before the fish entered the estuary (site of capture). Taken together, these data suggest that $A$. marinus is catadromous. Results indicated that $A$. zebra uses a chemically uniform habitat at both collection localities (Fig. 4), although results should be corroborated by future studies because $A$. zebra 
245 individuals assayed were juveniles. Nevertheless, specimens from Tocoihue River appear to have

246 been exposed to marine influence compared to those from Lake Caro (Table S2), suggesting

247 preference for freshwater residency, but capacity for osmoregulation when salinity levels

248 increase.

249 G. maculatus individuals were sampled from the same site as some specimens of A. zebra

250 (Tocoihue). However, among four specimens assayed, three showed the highest variation in

251 Sr:Ca compared to any other galaxiid species analysed (Fig. 3) with evidence of both

252 catadromous and amphidromous transitions (Table 1). The G. maculatus specimen in Fig. 4 was

253 caught in the lower reach of the Tocoihue River in an area with strong tidal influence. The otolith

254 profile suggests an amphidromous life-cycle with intermediate $\mathrm{Sr}: \mathrm{Ca}$ levels in the primordium

255 followed by increases in $\mathrm{Sr}$ :Ca ratio and subsequent decrease to lower $\mathrm{Sr}$ :Ca levels. A fourth

256 specimen of G. maculatus showed no major Sr:Ca fluctuations across the otolith transect (Table

257 S2), suggesting that this individual did not drift out to the ocean during its larval stage.

258 Only one specimen from the low-elevation coastal Palos Lake was assayed for G. platei,

259 and results indicate freshwater residency as revealed by uniformly low Sr:Ca ratios across the

260 entire otolith transect (Fig. 3 and 4).

261

262 Introduced salmonids

263 This study supports established anadromy in O. tshawytscha in Patagonia, as previously

264 shown by other authors (Ciancio et al., 2005; Correa \& Gross, 2008; Arismendi \& Soto, 2012;

265 Araya et al., 2014). Data are consistent with changes in Sr:Ca concentration levels that suggest

266 hatching in freshwater, migration to areas with marine influence followed by a return to inland,

267 freshwater areas to spawn (Fig. 4). O. tshawytscha specimens collected from the Simpson River 
268 do not show as much variation as other O. tshawytscha from this study most likely because these

269 fish were all juveniles that had not yet migrated.

270 The two parr O. kisutch analysed revealed one substantial Sr:Ca shift between birth and

271 time of capture. Both otolith profiles showed relatively high Sr:Ca signatures around the core

272 that diminished substantially towards the edges (Fig. 4). These specimens where caught during

273 the summer, about $55 \mathrm{~km}$ upstream of the Baker River's mainstream. The observed pattern is

274 consistent with maternal effects imprinting a marine signature near the core, which is formed

275 during the yolk absorption phase (Kalish, 1990; Volk et al., 2000; Zimmerman \& Reeves, 2002).

276 Our results add to the sparse documentation of the establishment of self-sustaining $O$. kisutch

277 populations in southern Patagonia (Górski et al., 2016). Conversely, O. mykiss exhibited a

278 pattern consistent with freshwater residency and minor Sr:Ca fluctuations over the entire life 279 cycle (Fig. 3 and 5).

280 Evidence of at least two different life cycle patterns emerged for S. trutta specimens 281 caught at three different locations. The Sr:Ca transect of juveniles from Lake Caro and adults 282 from Lake Palos showed a pattern consistent with continuous residency in freshwater (Fig. 3 and 283 5) whereas S. trutta from Baker River showed higher values at the primordium (Fig. 4).

285 Discussion

286 This study quantitatively identified significant transitions across otolith profiles using 287 regression trees on Sr:Ca ratios. Native galaxiids showed considerable variation in putative 288 habitat shifts when compared across species, with some species exhibiting differences at the 289 population and individual levels, indicating a high degree of plasticity. Of five native galaxiids 290 examined, evidence was found for one catadromous (A. marinus) and two facultatively 
291 amphidromous or catadromous species (G. maculatus and A.taeniatus). Nonnative salmonids

292 have established populations with a broad array of migratory life histories, reflective of those

293 found in their native ranges. Patterns consistent with anadromy were present in three $(O$.

294 tshawytscha, O. kisutch, S. trutta) of four species included in this study.

295 Several species appear to regularly use habitats with different levels of marine influence.

296 Otolith profiles that showed variation under the most restrictive analytical conditions were those

297 most likely to exhibit large-scale habitat shifts between different environments and salinity levels

298 (A. taeniatus, A. marinus, G. maculatus, O. tshawytscha). Otolith profiles that varied under less

299 stringent conditions hinted at subtler shifts within habitat types.

300 Results suggest a preponderance of euryhaline (i.e. broad tolerance to different salinity

301 levels) and facultative diadromous species among native galaxiids and introduced salmonids in

302 Patagonia. The inferences on species migratory status by population, reported in Table 1, suggest

303 that some species display a diverse range of life history strategies (facultative diadromy),

304 coinciding with an increasing number of studies reporting flexibility in diadromous patterns for

305 several fishes (Hicks, Closs \& Swearer, 2010; Augspurger, Warburton \& Closs, 2015; Górski et

306 al., 2015). These studies included Southern Hemisphere fishes and revealed the variability of

307 resident/migratory life histories within species. This work reinforces the shift from the classical

308 view that tended to categorize species as exclusively resident or migratory

309 Otolith microchemistry for introduced salmonids suggested that some species have

310 established movement strategies similar to those in their native ranges. The successful

311 establishment of anadromous exotic salmonids in Chile reinforces the hypothesis that the biotic

312 and abiotic conditions required for diadromy to be maintained (Gross, Coleman \& McDowall,

313 1988) are present in Chilean waters. 
314 Current knowledge of preferred habitats and common life-histories in native continental

315 fishes of Chile indicates that approximately $30 \%$ of the species have a broad halohabitat

316 distribution, including species adapted to life in saltpans, estuaries and a variety of different

317 diadromous strategies (Table S1). On the other hand, only about 9\% of fishes around the world

318 are considered euryhaline and just a few display some form of diadromous migrations (Nelson,

319 2006; Schultz \& McCormick, 2013). Estuaries of temperate regions often stimulate the evolution

320 of adaptation from seawater to freshwater and can be seen as hotspots for transitions (i.e. regions

321 with a high number of species with propensity for movement between saltwater and freshwater)

322 (Schultz \& McCormick, 2013; Ruiz-Jarabo et al., 2016).

323 The likelihood of freshwater colonization is affected by multiple factors. Colonization

324 probability increases when habitats are disturbed by extreme events like glaciation, drought,

325 volcanic and anthropogenic activities. Extreme events can leave freshwater habitats with low

326 levels of biodiversity and prone to infiltration and acclimation from migratory or coastal

327 euryhaline fishes. Habitats with wide temporal or spatial ranges in salinity also provide good

328 hotspots for transitions because the acclimation response depends on the physiology of the fish

329 and the timescale of fluctuations. Lower temperatures are prevalent at mid latitudes and these

330 conditions favor higher rates of colonization, since salinity and temperature interact to affect

331 energetic demands, ion uptake rate and membrane permeability of fishes (Greenwood, 1975 as

332 cited in Bamber \& Henderson, 1988, McDowall, 1988; Lee \& Bell, 1999; Schultz \&

333 McCormick, 2013).

334 Specific physiological adaptations can also facilitate freshwater colonization propensity

335 in fishes. For example, specialized gills allow movement between saltwater and freshwater (Lee

336 \& Bell, 1999; Schultz \& McCormick, 2013) (i.e. atherinids). Further, certain groups of 
337 diadromous fishes (e.g. galaxiids, salmonids) demonstrate plasticity in osmoregulation.

338 Diadromous species migrate between saltwater and freshwater habitats at different stages of their

339 life-cycles, but as shown in this study, some switch to a resident strategy. Euryhalinity and

340 diadromy can therefore be seen as key innovations that enable lineages to radiate into new

341 environments (Bamber \& Henderson, 1988; Lee \& Bell, 1999; McDowall, 2001; Schultz \&

342 McCormick, 2013).

343 Diadromous migrations mostly promote gene flow among populations, but can also lead

344 to landlocking, isolation and cladogenesis (McDowall, 2001). Habitat characteristics of coastal

345 zones composed of estuaries separated by long stretches of open shore, may facilitate isolation

346 and landlocking of diadromous and euryhaline fishes into more stable habitats. For example,

347 very high within-species genetic diversity was found in G. maculatus across its New Zealand

348 range and along most of the Chilean coast except between $30^{\circ} \mathrm{S}$ and $42^{\circ} \mathrm{S}$ in Chile, where $G$.

349 maculatus displayed lower genetic diversity and higher levels of genetic structure (Lee \& Bell,

350 1999; Waters, Dijkstra \& Wallis, 2000; González-Wevar et al., 2015). Higher levels of genetic

351 structure found within populations of G. maculatus in Chile were hypothesized to depend on

352 glaciation history, but variation in coastal configurations and oceanographic regimes can also be

353 linked to population differentiation and isolation.

354 Comparative otolith microchemistry analysis suggested that fishes of southern Chile may

355 require a heterogeneous and spatially connected environment to complete their life-cycles. These

356 temperate areas may be considered a favourable environment for the development and

357 maintenance of migratory strategies in fishes (i.e. galaxiids) and could provide useful tools to

358 evaluate the influence of habitat discontinuities and biogeography on the spatial distribution,

359 colonization rates and genetic diversity of euryhaline and diadromous fishes alike (i.e. atherinids, 
360 galaxiids, salmonids). Examining recent freshwater invasions can yield insights into the

361 osmoregulatory systems that enable the invasion of freshwater habitats and offer excellent

362 systems for observing evolutionary adaptation in progress (Lee \& Bell, 1999; González-Wevar et

363 al., 2015).

364

365 Limitations and further studies

366 Some otolith results may have been influenced by maternal effects or induced by local

367 temporal variation in water chemistry. Further studies may indicate whether the higher Sr:Ca

368 ratios in primordia observed in some species could be attributable to maternal effects or other

369 causes. For example, although the mechanisms are not completely understood, physiological

370 constraints in early ontogeny could increase the rate of $\mathrm{Sr}$ absorption into the calcium carbonate

371 matrix of the otolith (de Pontual et al., 2003). Also, as the Baker river system is influenced by a

372 large ice field (Campo de Hielo Norte), high amounts of glacier flour (suspended solids) can

373 contribute to increased salinity levels in water that flows into the estuary (Vargas, Aguayo \&

374 Torres, 2011; Marín et al., 2013). These seasonal salinity changes may promote the uptake of $\mathrm{Sr}$

375 into the otolith matrix and confound the assumption of low $\mathrm{Sr}$ in freshwater environments

376 (Zimmerman, 2005). Therefore, even though $\mathrm{Sr}$ has been traditionally recognized as a very

377 robust marker to discriminate between marine and freshwater environments, several recent

378 studies have indicated that factors such as species-specific variation, environmentally-mediated

379 physiological processes, individual variation and the interaction of different environmental

380 factors can influence Sr uptake into the otolith matrix (Elsdon \& Gillanders, 2002b, 2004;

381 Gillanders, 2005; Doubleday et al., 2015; Sturrock et al., 2015).

382 This study suggests that considerable variation in migratory life history may exist in 
383 Chilean fishes, but its inferential scope is restricted by the limited number of samples, which

384 were collected for other research purposes (see Correa \& Hendry, 2012; Correa et al., 2012; Alò

385 et al., 2013) and by lack of water chemistry samples. The interpretations given for diadromous

386 and resident patterns are limited to the observed Sr:Ca shifts in the otolith profiles and should be

387 considered carefully especially when referring to the extent of movement between different

388 habitats. Species-specific reference values for Sr:Ca ratios and a more comprehensive sampling

389 will be needed to quantify the extent of fish movements within Chilean continental waters in

390 more detail. Ideally, a variety of different field techniques (natural markers such as stable

391 isotopes, otoliths, statoliths for lampreys, or scales; as well as molecular markers, tagging,

392 trapping and tracking) and laboratory methods (e.g. movement physiology, swimming

393 performance, metabolism) (see Dingle, 2014) should be used to characterize daily and seasonal

394 migration patterns. Incorporation of this knowledge could improve design and operation of fish

395 passage structures to benefit native fishes (Laborde et al., 2016). However, because information

396 on fish life history is lacking for native fishes in Chile and elsewhere in the temperate Southern

397 Hemisphere, fish passage design is generally based solely on professional judgment (Wilkes et

398 al., 2018).

399

400 Conservation issues

401 This study could help refine the conservation priorities for freshwater fishes in southern

402 Chile. Given high endemism and the likelihood of dependence on diadromous behaviour,

403 potential threats to fishes from fragmentation of river-to-estuary networks are correspondingly

404 high. Hydroelectric power development causes loss of hydrological connectivity and alteration of

405 the river flow regime, disproportionately affecting fishes with migratory life histories (Fullerton 
406 et al., 2010). Comparative otolith microchemistry results underscore the variation in life history

407 strategies that should be accounted for when planning to manipulate water-flow for hydroelectric

408 developments. Diadromous species depend on the habitat diversity and complexity created by

409 unobstructed watersheds and are locally extirpated when barriers preclude movement to essential

410 habitat. Additionally, anthropogenic barriers and alterations to water flow (e.g., hydropeaking)

411 may also negatively affect landlocked populations because such structures disrupt successful

412 reproduction, recruitment and habitat quality (Alò \& Turner, 2005; Garcia et al., 2011). Current

413 hydropower capacity in Chile ( $\sim 6.000$ megawatts of energy connected to the central grid) is

414 expected to increase $(\sim 11.000$ megawatts by the year 2020$)$ building approximately 900

415 additional hydroelectric power plants due to legislative privileges given to hydroelectric

416 investors such as i) water allocation rights favouring in-stream productive uses; ii) ease for

417 hydropower investors to acquire riverside land; iii) specific tax easements and deferments for

418 hydroelectric investors; and iv) taxes imposed for "ecological" in-stream uses (Prieto \& Bauer,

419 2012; Santana et al., 2014; Toledo, 2014). Preliminary studies have identified most of the

420 hydroelectric potential in the south-eastern sector of the country, in the sub-basins with high

421 elevations and discharge (Santana et al., 2014). Development is slated in basins that harbour the

422 majority of native fish species diversity.

423 Ongoing spread of exotic species threatens native species through negative interactions

424 including predation, competition, behavioural inhibition and homogenization (Correa \& Gross,

425 2008; Penaluna, Arismendi \& Soto, 2009; Correa \& Hendry, 2012b; Correa, Bravo \& Hendry,

426 2012; Habit et al., 2012; Arismendi et al., 2014; Vargas, Arismendi \& Gomez-Uchida, 2015). In

427 particular, establishment of migration runs of $O$. tshawytscha and $O$. kisutch could trigger

428 additional threats such as the shift of significant amounts of marine-derived nutrients to 
429 previously oligotrophic environments (Helfield \& Naiman, 2001; Arismendi \& Soto, 2012) and

430 increased competition for limited resources with the native diadromous species. Non-native

431 salmon and trout are also likely to be negatively affected by future hydroelectric dams.

432 Additional hydropower development will almost certainly impact a flourishing tourism industry 433 supported by salmonid recreational fisheries (Arismendi \& Nahuelhual, 2007; Vigliano, Alonso 434 \& Aquaculture, 2007).

435 The evolutionary processes that allowed dispersal and colonization of Patagonian fishes 436 are influenced by the region's unique geography, climate, and geological processes. To ensure 437 conservation of native freshwater, diadromous, and commercially relevant sport fisheries, 438 managers will have to carefully designate and protect critical habitats, and in many cases mitigate obstruction of river flows imposed by dams with appropriate fish passage structures

440 (Wilkes, Mckenzie \& Webb, 2017). Long-term monitoring should also be a priority to

441 understand the broad impacts of hydropower development on aquatic biodiversity.

\section{Acknowledgements}

We are thankful to A.P. Bravo, I.Y. Quinteros, M. Soto-Gamboa, and L. Caputo for assistance in the field, and to M.L. Guillemin for providing field equipment. S. Platania, S.

Barkalow and M. Brandenburg assisted with laboratory procedures and logistics. The Museum of

447 Southwestern Biology at UNM provided curatorial assistance. Laboratorio de Dendrocronología

448 y Cambio Global at UACh allowed use of its microscopy facility. We thank P. Marquet for

449 revising an earlier version of this manuscript, A. Castillo for help with GIS mapping, E. Habit for

450 a useful discussion, the anonymous reviewers and PeerJ editor M.A. Esteban that significantly

451 helped to improve this manuscript. 


\section{References}

455 Alò D., Correa C., Arias C., Cárdenas L. 2013. Diversity of Aplochiton Fishes (Galaxiidea) and 456 the Taxonomic Resurrection of A. marinus. PLoS ONE 8:e71577. DOI:

457

Alò D., Turner TF. 2005. Effects of Habitat Fragmentation on Effective Population Size in the Endangered Rio Grande Silvery Minnow. Conservation Biology 19:1138-1148. DOI: 10.1111/j.1523-1739.2005.00081.x.

461

Araya M., Niklitschek EJ., Secor DH., Piccoli PM. 2014. Partial migration in introduced wild 462 chinook salmon (Oncorhynchus tshawytscha) of southern Chile. Estuarine, Coastal and Shelf Science 149:87-95. DOI: 10.1016/j.ecss.2014.07.011.

Arismendi I., Nahuelhual L. 2007. Non-native Salmon and Trout Recreational Fishing in Lake Llanquihue, Southern Chile : Economic. Reviews in Fisheries Science 15:311-325. DOI: $10.1080 / 10641260701484655$.

Arismendi I., Penaluna BE., Dunham JB., García de Leaniz C., Soto D., Fleming IA., GomezUchida D., Gajardo G., Vargas P V., León-Muñoz J. 2014. Differential invasion success of salmonids in southern Chile: patterns and hypotheses. Reviews in Fish Biology and Fisheries. DOI: 10.1007/s11160-014-9351-0.

Arismendi I., Soto D. 2012. Are salmon-derived nutrients being incorporated in food webs of invaded streams? Evidence from southern Chile. Knowledge and Management of Aquatic Ecosystems 405:1-6. DOI: 10.1051/kmae/2012009.

Arkhipkin AI., Schuchert PC., Danyushevsky L. 2009. Otolith chemistry reveals fine population structure and close affinity to the Pacific and Atlantic oceanic spawning grounds in the 
476

477

478

479

480

481

482

483

484

485

486

487

488

489

490

491

492

493

494

495

496

497

migratory southern blue whiting (Micromesistius australis australis). Fisheries Research 96:188-194. DOI: 10.1016/j.fishres.2008.11.002.

Ashford JR., Jones CM., Hofmann E., Everson I., Moreno C., Duhamel G., Williams R. 2005. Can otolith elemental signatures record the capture site of Patagonian toothfish (Dissostichus eleginoides), a fully marine fish in the Southern Ocean? Canadian Journal of Fisheries and Aquatic Sciences 62:2832-2840. DOI: 10.1139/F05-191.

Augspurger JM., Warburton M., Closs GP. 2015. Life-history plasticity in amphidromous and catadromous fishes : a continuum of strategies. Reviews in Fish Biology and Fisheries 27:177-192. DOI: 10.1007/s11160-016-9463-9.

Bamber RN., Henderson PA. 1988. Pre-adaptive plasticity in atherinids and the estuarine seat of teleost evolution. Journal of Fish Biology 33:17-23. DOI: 10.1111/j.10958649.1988.tb05554.x.

Breiman L., Friedman J., Stone CJ., Olshen RA. 1984. Classification and regression trees. CRC Press.

Campana S. 1999. Chemistry and composition of fish otoliths: pathways, mechanisms and applications. Marine Ecology Progress Series.

Campana SE. 2005. Otolith science entering the 21st century. Marine and Freshwater Research 56:485. DOI: $10.1071 / \mathrm{MF} 04147$.

Chang CW., Iizuka Y., Tzeng WN. 2004. Migratory environmental history of the grey mullet Mugil cephalus as revealed by otolith $\mathrm{Sr}$ : Ca ratios. Marine Ecology Progress Series 269:277-288.

Ciancio JE., Pascual MA., Botto F., Amaya-Santi M., O’Neal S., Riva Rossi C., Iribarne O. 
498

499

500

501

502

503

504

505

506

507

508

509

510

511

512

513

514

515

516

517

518

519

2008. Stable isotope profiles of partially migratory salmonid populations in Atlantic rivers of Patagonia. Journal of Fish Biology 72:1708-1719. DOI: 10.1111/j.10958649.2008.01846.x.

Ciancio JE., Pascual M a., Lancelotti J., Rossi CMR., Botto F. 2005. Natural Colonization and Establishment of a Chinook Salmon, Oncorhynchus tshawytscha, Population in the Santa Cruz River, an Atlantic Basin of Patagonia. Environmental Biology of Fishes 74:219-227. DOI: $10.1007 / \mathrm{s} 10641-005-0208-1$.

Correa C., Bravo AP., Hendry AP. 2012. Reciprocal trophic niche shifts in native and invasive fish: Salmonids and galaxiids in Patagonian lakes. Freshwater Biology 57:1769-1781. DOI: 10.1111/j.1365-2427.2012.02837.x.

Correa C., Gross MR. 2008. Chinook salmon invade southern South America. Biological Invasions 10:615-639. DOI: 10.1007/s10530-007-9157-2.

Correa C., Hendry AP. 2012a. Invasive salmonids and lake order interact in the decline of puye grande Galaxias platei in western Patagonia lakes. Ecological Applications 22:828-842. DOI: $10.1890 / 11-1174.1$.

Correa C., Hendry AP. 2012b. Invasive salmonids and lake order interact in the decline of puye grande Galaxias platei in western Patagonia lakes. Ecological Applications 22:828-842. DOI: $10.1890 / 11-1174.1$.

De'ath G. 2002. Multivariate regression trees: A new technique for modeling speciesenvironment relationships. Ecology 83:1105-1117. DOI: 10.1890/00129658(2002)083[1105:MRTANT]2.0.CO;2.

Diario Oficial de la Republica de Chile. 2008. Tercer Proceso de Clasificacion de Especies segun 
su Estado de Conservacion. 39.100:4-5.

521 Dingle H. 2014. Migration: The Biology of Life on the Move. New York: Oxford University 522 Press, Inc.

523 Dingle HD., Drake VA. 2007. What Is Migration? BioScience 57:113-121.

524 Doubleday A., Ye Q., Gillanders BM., Izzo C. 2015. Partial migration : growth varies between 525 resident and migratory fish.

526 Dyer BS. 2000. Systematic review and biogeography of the freshwater fishes of Chile. Estud. $527 \quad$ Oceanol 19:77-98.

528 Elsdon T., Gillanders B. 2002a. Interactive effects of temperature and salinity on otolith 529 chemistry: challenges for determining environmental histories of fish. Canadian Journal of $530 \quad$ Fisheries ... 1808:1796-1808. DOI: 10.1139/F02-154.

531 Elsdon T., Gillanders B. 2002b. Interactive effects of temperature and salinity on otolith 532 chemistry: challenges for determining environmental histories of fish. Canadian Journal of $533 \quad$ Fisheries \& Aquatic Sciences 59:1796-1808.

534 Elsdon TS., Gillanders BM. 2004. Fish otolith chemistry influenced by exposure to multiple 535 environmental variables. Journal of Experimental Marine Biology and Ecology 313:269536 284. DOI: $10.1016 /$ j.jembe.2004.08.010.

537 Fowler AJ., Campana SE., Jones CM., Thorrold SR. 1995. Experimental assessment of the effect 538 of temperature and salinity on elemental composition of otoliths using laser ablation $539 \quad$ ICPMS. Canadian Journal of Fisheries \& Aquatic Sciences 52:1431-1441.

540 Fullerton AH., Burnett KM., Steel EA., Flitcroft RL., Pess GR., Feist BE., Torgersen CE., Miller 541 DJ., Sanderson BL. 2010. Hydrological connectivity for riverine fish: measurement 
542 challenges and research opportunities. Freshwater Biology 55:2215-2237. DOI:

$543 \quad 10.1111 / \mathrm{j} .1365-2427.2010 .02448 . x$.

544 Garcia A., Jorde K., Habit EM., Caamano D., Parra O. 2011. Downstream Environmental Effects

545 of Dam Operations: Changes in Habitat Quality for Native Fish Species. 27:312-327. DOI:

$546 \quad 10.1002 /$ rra.

547 Gillanders BM. 2005. Using elemental chemistry of fish otoliths to determine connectivity

548 between estuarine and coastal habitats. Estuarine, Coastal and Shelf Science 64:47-57.

$549 \quad$ DOI: $10.1016 /$ j.ecss.2005.02.005.

550 González-Wevar C., Salinas P., Hüne M., Segovia N., Vargas-Chacoff L., Oda E., Poulin E.

5512015 . Contrasting Genetic Structure and Diversity of Galaxias maculatus (Jenyns, 1848)

552 Along the Chilean Coast: Stock Identification for Fishery Management. Journal of Heredity

553 106:439-447. DOI: 10.1093/jhered/esv005.

554 Górski K., González J., Vivancos A., Habit EM., Ruzzante DE. 2016. Young-of-the-year Coho

555 Salmon Oncorhynchus kisutch recruit in fresh waters of remote Patagonian fjords in

556 southern Chile ( $\left.51^{\circ} \mathrm{S}\right)$. Biological Invasions. DOI: 10.1007/s10530-016-1341-9.

557 Górski K., Habit EM., Pingram MA., Manosalva AJ. 2015. Variation of the use of marine

558 resources by Galaxias maculatus in large Chilean rivers. Hydrobiologia. DOI:

$559 \quad 10.1007 / \mathrm{s} 10750-015-2542-4$.

560 Greenwood PH. 1975. A History of Fishes. London.

561 Gross MR. 1987. Evolution of diadromy in fishes. American Fisheries Society Symposium 1:145625.

563 Gross MR., Coleman RM., McDowall RM. 1988. Aquatic Productivity and the Evolution of 

Diadromous Fish Migration. Science 239:1291-1293.

565 Habit E., Dyer BS., Vila I. 2006. Current state of knowledge of freshwater fishes of Chile. $566 \quad$ Gayana 70:100-113.

567 Habit E., Gonzalez J., Ruzzante DE., Walde SJ. 2012. Native and introduced fish species

568 richness in Chilean Patagonian lakes: Inferences on invasion mechanisms using salmonid-

569 free lakes. Diversity and Distributions 18:1153-1165. DOI: 10.1111/j.1472-

$570 \quad$ 4642.2012.00906.x.

571 Habit EM., Victoriano P. 2005. Peces de agua dulce de la Cordillera de la Costa. In:

572 Biodiversidad y Ecología de la Cordillera de la Costa de Chile. 374-389.

573 Halden NM., Mejia SR., Babaluk JA., Reist JD., Kristofferson AH., Campbell JL., Teesdale WJ.

574 2000. Oscillatory zinc distribution in Arctic char (Salvelinus alpinus) otoliths : The result of 575 biology or environment? Fisheries Research 46:289-298.

576 Helfield JM., Naiman RJ. 2001. Effects of Salmon-Derived Nitrogen on Riparian Forest Growth 577 and Implications for Stream Productivity. Ecology 82:2403-2409.

578 Hicks AS., Closs GP., Swearer SE. 2010. Otolith microchemistry of two amphidromous 579 galaxiids across an experimental salinity gradient: A multi-element approach for tracking 580 diadromous migrations. Journal of Experimental Marine Biology and Ecology 394:86-97.

$581 \quad$ DOI: $10.1016 /$ j.jembe.2010.07.018.

582 Howland KL., Tonn WM., Babaluk J a., Tallman RF. 2001. Identification of Freshwater and 583 Anadromous Inconnu in the Mackenzie River System by Analysis of Otolith Strontium. 584 Transactions of the American Fisheries Society 130:725-741. DOI: 10.1577/15488659(2001)130<0725:IOFAAI>2.0.CO;2. 
586 Instituto Nacional de Estadisticas. 2015.Caracteristicas generales de los principales rios de Chile.

587 Available at http://historico.ine.cl/medioambiente/descargas/2015/xls/CAP5_AGUA.xlsx

588 IUCN. 2015.The IUCN Red List of Threatened Species. Available at www.iucnredlist.org

$589 \quad$ (accessed May 13, 2016).

590 Joo Y-J., Kim CS., Yoo S-H. 2015. Energy Consumption, Co2 Emission, and Economic Growth:

591 Evidence from Chile. International Journal of Green Energy 12:543-550. DOI:

$592 \quad 10.1080 / 15435075.2013 .834822$.

593 Kalish JM. 1990. Use of Otolith Microchemistry to Distinguish the Progeny of Sympatric

$594 \quad$ Anadromous and Non-anadromous Salmonids. 88:657-666.

595 Kraus R. 2004. Incorporation of strontium into otoliths of an estuarine fish. Journal of

596 Experimental Marine Biology and Ecology 302:85-106. DOI:

$597 \quad 10.1016 /$ j.jembe.2003.10.004.

598 L'opez-de-Lacalle. 2016. tsoutliers: Detection of Outliers in Time Series.

599 Laborde A., Gonzalez A., Sanhueza C., Arriagada P., Wilkes MA., Habit EM., Link O. 2016.

600 Hydropower Development, Riverine Connectivity, and Non-sport Fish Species: criteria for

601 Hydraulic Design of Fishways. River Research and Applications 32:1949-1957.

602 Lee CE., Bell M a. 1999. Causes and consequences of freshwater invasions. Trends in Ecology \& $603 \quad$ Evolution 14:284-288.

604 Limburg KE. 1995. Otolith strontium traces environmental history of subyearling American shad 605 Alosa sapidissima. Marine Ecology Progress Series 119:25-35. DOI: 10.3354/meps119025.

606 Limburg KE., Landergren P., Westin L., Elfman M., Kristiansson P. 2001. Flexible modes of 607 anadromy in Baltic sea trout : making the most of marginal spawning streams. Journal of 
Fish Biology 59:682-695. DOI: 10.1006/jfbi.2001.1681.

609 Marín VH., Tironi A., Alejandra M., Contreras M. 2013. Modeling suspended solids in a 610 Northern Chilean Patagonia glacier-fed fjord: GLOF scenarios under climate change 611 conditions. Ecological Modelling 264:7-16. DOI: 10.1016/j.ecolmodel.2012.06.017.

612 McDowall RM. 1971. The galaxiid fishes of South America. Zoological Journal of the Linnean 613 Society 50:33-73. DOI: 10.1111/j.1096-3642.1971.tb00751.x.

614 McDowall RM. 1988. Diadromy in Fishes. Portland, Oregon: Timber Press.

615 McDowall RM. 1992. Diadromy : Origins and Definitions of Terminology. Copeia 1992:248616251.

617 McDowall RM. 1997. The evolution of diadromy in fishes (revisited) and its place in 618 phylogenetic analysis. Reviews in Fish Biology and Fisheries 7:443-462. DOI:

$619 \quad 10.1023 / \mathrm{A}: 1018404331601$.

620 McDowall RM. 2001. Diadromy, diversity and divergence: Implications for speciation processes 621 in fishes. Fish and Fisheries 2:278-285. DOI: 10.1046/j.1467-2960.2001.00050.x.

622 McDowall RM. 2002a. The origin of salmonid fishes: Marine, freshwater ... or neither? Reviews 623 in Fish Biology and Fisheries 11:171-179. DOI: 10.1023/A:1020370328194.

624 McDowall RM. 2002b. Accumulating evidence for a dispersal biogeography of southern cool 625 temperate freshwater fishes. Journal of Biogeography 29:207-219. DOI: 10.1046/j.1365$626 \quad 2699.2002 .00670 . x$

627 Ministerio del Medio Ambiente. 2013.Especies: Clasificacion segun estado de conservacion. $628 \quad$ Available at 629 http://www.mma.gob.cl/clasificacionespecies/doc/UNIFICADA_de_Especie_Estado_Conse 
631 Myers GS. 1949. Usage of anadromous, catadromous and allied terms for migratory fishes. 632 Copeia 1949:89-97.

633 Nelson JS. 2006. Fishes of the world. Hoboken, New Jersey: John Wiley \& Sons Inc.

634 Penaluna BE., Arismendi I., Soto D. 2009. Evidence of Interactive Segregation between 635 Introduced Trout and Native Fishes in Northern Patagonian Rivers, Chile. Transactions of 636 the American Fisheries Society 138:839-845. DOI: 10.1577/T08-134.1.

637 de Pontual H., Lagardere F., Amara R., Bohn M., Ogor A. 2003. Influence of ontogenetic and 638 environmental changes in the otolith microchemistry of juvenile sole (Solea solea). Journal 639 of Sea Research 50:199-210. DOI: 10.1016/S1385-1101(03)00080-7.

640 Pracheil BM., Hogan JD., Lyons J., McIntyre PB. 2014. Using Hard-Part Microchemistry to 641 Advance Conservation and Management of North American Freshwater Fishes. Fisheries $642 \quad 39: 451-465$. DOI: 10.1080/03632415.2014.937858.

643 Prieto M., Bauer C. 2012. Hydroelectric power generation in Chile : an institutional critique of 644 the neutrality of market mechanisms. Water International 37:131-146. DOI: $10.1080 / 02508060.2012 .662731$.

646 Proctor CH., Thresher RE. 1998. Effects of specimen handling and otolith preparation on 647 concentration of elements in fish otoliths. Marine Biology 131:681-694. DOI: $648 \quad 10.1007 / \mathrm{s} 002270050360$.

649 Pulido F. 2007. The Genetics and Evolution of Avian Migration. Bio Science 57:165-174.

650 Riva-Rossi C., Pascual MA., Babaluk JA., Garcia-Asorey M., Halden NM. 2007. Intra651 population variation in anadromy and reproductive life span in rainbow trout introduced in 
the Santa Cruz River, Argentina. Journal of Fish Biology 70:1780-1797.

653 Ruiz-Jarabo I., Gonzï $\iota^{1 / 2}$ lez-Wevar CA., Oyarzï $i^{1 / 2 n}$ R., Fuentes J., Poulin E., Bertrï $i^{1 / 2 n}$ C., 654 Vargas-Chacoff L. 2016. Isolation driven divergence in osmoregulation in Galaxias 655 maculatus (Jenyns, 1848) (Actinopterygii: Osmeriformes). PLoS ONE 11:1-21. DOI: $656 \quad$ 10.1371/journal.pone.0154766.

657 Santana C., Falvey M., Ibarra M., Garcia M. 2014. Energias Renovables en Chile. El potencial 658 eolico, solar e hidroelectrico de Arica a Chiloe. Santiago de Chile.

659 Schultz ET., McCormick SD. 2013. Euryhalinity in An Evolutionary Context. In: EURYHALINE 660 FISHES. Fish Physiology. Amsterdam (The Netherlands) and Boston (Massachusetts): 661 Elsevier, 477-533. DOI: http://dx.doi.org/10.1016/B978-0-12-396951-4.00010-4.

662 Secor DH., Rooker JR. 2000. Is otolith strontium a useful scalar of life cycles in estuarine 663 fishes? Fisheries Research 46:359-371.

664 Strobl C. 2009. An Introduction to Recursive Partitioning: Rationale, Application and 665 Characteristics of Classification and Regression Trees, Bagging and Random Forests. 666 Psychol Methods 14:323-348. DOI: 10.1037/a0016973.An.

667 Sturgeon RE., Willie SN., Yang L., Greenberg R., Spatz RO., Chen Z., Scriver C., Clancy V., 668 Lam JW., Thorrold S. 2005. Certification of a fish otolith reference material in support of 669 quality assurance for trace element analysis. Journal of Analytical Atomic Spectrometry $670 \quad 20: 1067$. DOI: $10.1039 / b 503655 k$.

671 Sturrock AM., Hunter E., Milton JA., Johnson RC., Waring CP., Trueman CN. 2015.

672 Quantifying physiological influences on otolith microchemistry. Methods in Ecology and 673 Evolution 6:806-816. DOI: 10.1111/2041-210X.12381. 
674 Therneau TM., Atkinson EJ. 1997. An Introduction to Recusive Partitioning Using the RPART 675 Routines. Mayo Foundation: Technical Report:1-62.

676 Toledo HR. 2014. Ecología política y represas : elementos para el análisis del Proyecto

677 HidroAysén en la Patagonia chilena 1. Revista de Geografia Norte Grande 57:161-175.

678 Tzeng WN., Severin KP., Wickstrom H. 1997. Use of otolith microchemistry to investigate the 679 environmental history of European eel Anguilla anguilla. Marine Ecology-Progress Series $680 \quad$ 149:73-81. DOI: $10.3354 /$ meps 149073.

681 Tzeng WN., Tsai YC. 1994. Changes in otolith microchemistry of the japanese eel,_Anguilla

682 japonica_, during its migration from the ocean to the river of Taiwan. Journal of Fish $683 \quad$ Biology 45:671-683.

684 Vargas CA., Aguayo M., Torres R. 2011. Allochthonous subsidies of organic matter across a 685 lake - river - fjord landscape in the Chilean Patagonia: Implications for marine zooplankton 686 in inner fjord areas. Continental Shelf Research 31:187-201. DOI:

687 10.1016/j.csr.2010.06.016.

688 Vargas P V., Arismendi I., Gomez-Uchida D. 2015. Evaluating taxonomic homogenization of 689 freshwater fish assemblages in Chile. Revista Chilena de Historia Natural. DOI: $690 \quad 10.1186 / \mathrm{s} 40693-015-0046-2$.

691 Vigliano PH., Alonso MF., Aquaculture M. 2007. Salmonid Introductions in Patagonia: A Mixed 692 Blessing. Dordrecht: Springer Netherlands. DOI: 10.1007/978-1-4020-6148-6_17.

693 Vignon M. 2015. Extracting environmental histories from sclerochronological structures 694 Recursive partitioning as a mean to explore multielemental composition of fish otolith. 695 Ecological Informatics 30:159-169. 
696 Vila I., Scott S., Mendez MA., Valenzuela F., Iturra P., Poulin E. 2011. Orestias gloriae, a new

697 species of cyprinodontid fish from saltpan spring of the southern high Andes (Teleostei:

698 Cyprinodontidae). Ichthyological Exploration of Freshwaters 22:345-353.

699 Volk EC., Blakley A., Schroder SL., Kuehner SM. 2000. Otolith chemistry reflects migratory

$700 \quad$ characteristics of Pacific salmonids: Using otolith core chemistry to distinguish maternal

$701 \quad$ associations with sea and freshwaters. Fisheries Research 46:251-266. DOI:

$702 \quad 10.1016 / \mathrm{S} 0165-7836(00) 00150-8$.

703 Waples RS., Zabel RW., Scheuerell MD., Sanderson BL. 2007. Evolutionary responses by native

704 species to major anthropogenic changes to their ecosystems: Pacific salmon in the Columbia

705 River hydropower system. Molecular Ecology 17:84-96. DOI: 10.1111/j.1365-

$706 \quad 294 X .2007 .03510 . x$.

707 Waters JM., Dijkstra LH., Wallis GP. 2000. Biogeography of a southern hemisphere freshwater

708 fish: How important is marine dispersal. Molecular Ecology 9:1815-1821. DOI:

$709 \quad$ 10.1046/j.1365-294X.2000.01082.x.

710 Wells BK., Rieman BE., Clayton JL., Horan DL., Jones CM. 2003. Relationships between water,

711 otolith, and scale chemistries of Westslope Cutthroat Trout from the Coeur d'Alene River,

712 Idaho: the potential application of hard-part chemistry to describe movements in freshwater.

713 Transactions of the American Fisheries Society 132:409-424.

714 Wilkes M., Baumgartner L., Boys C., Silva LGM., O’Connor J., Jones M., Stuart I., Habit E.,

715 Link O., Webb JA. 2018. Fish-Net: Probabilistic models for fishway planning, design and

716 monitoring to support environmentally sustainable hydropower. Fish and Fisheries:677-

717 697. DOI: $10.1111 /$ faf.12282. 
718 Wilkes M., Mckenzie M., Webb JA. 2017. Fish passage design for sustainable hydropower in the

719 temperate Southern Hemisphere: an evidence review. Reviews in Fish Biology and

$720 \quad$ Fisheries:1-19.

721 Wolff BS., Johnson BM., Landress CM. 2013. Classification of hatchery and wild fish using

722 natural geochemical signatures in otoliths, fin rays, and scales of an endangered catostomid.

723 Canadian Journal of Fisheries \& Aquatic Sciences 70:1775-1784.

724 Zimmerman CE. 2005. Relationship of otolith strontium-to-calcium ratios and salinity:

725 experimental validation for juvenile salmonids. Canadian Journal of Fisheries \& Aquatic

726 Sciences 62:88-97. DOI: 10.1139/F04-182.

727 Zimmerman CZ., Reeves GH. 2002. Identification of Steelhead and Resident Rainbow Trout

728 Progeny in the Deschutes River, Oregon, Revealed with Otolith Microchemistry.

729 Transactions of the American Fisheries Society 131:986-993. 
Figure 1

Map of sampled species and locations across Patagonia

Estimated distribution range for native Chilean galaxiids (shaded and dash lined polygons) and the sampling locations of specimens used in this study (dots) for a) genus Aplochiton, b) genus Galaxias, c) non-native fishes examined in this study. Made with Natural Earth. Free vector and raster map data @ naturalearthdata.com.
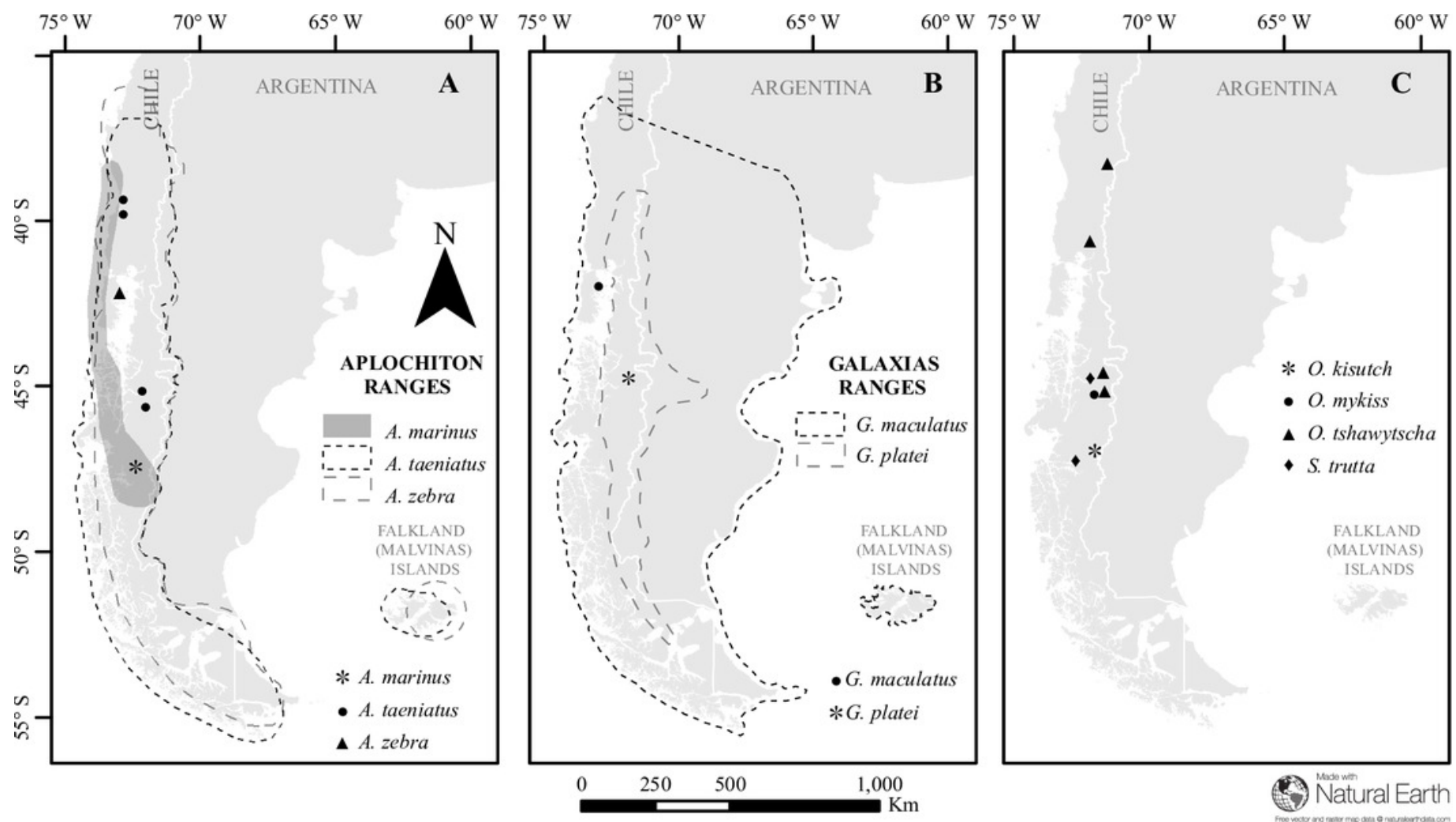


\section{Figure 2}

Idealized representations of resident and diadromous life-histories as expected in otolith microchemistry results.

The uppermost image depicts a schematic representation of an otolith, showing how growth rings accrue over time around the core and culminate at the edge. The number of distinct layers in the otolith depends on the age of the individual. The images below represent idealized time series data obtained by repeatedly measuring (via laser ablation and spectrometry) elemental strontium to calcium ( $\mathrm{Sr}: \mathrm{Ca}$ ) ratios across the otolith. Each box shows an expected time series for each life-history strategy 

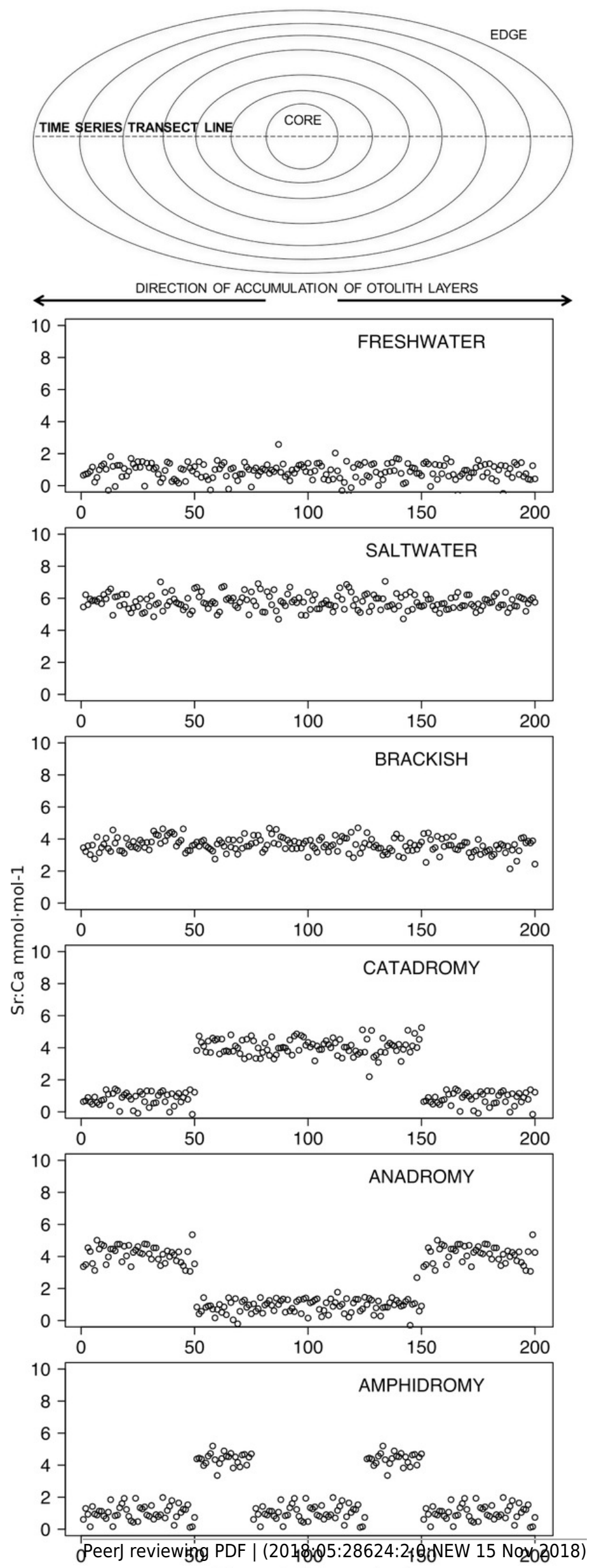
Transect Distance $(\mu \mathrm{m})$ 
Figure 3

Violin plot for Sr:Ca values

This plot reports the Sr:Ca values for otoliths grouped by species. Black dot = median, white line $=$ first to third quartile. Grey areas $=$ kernel density plot

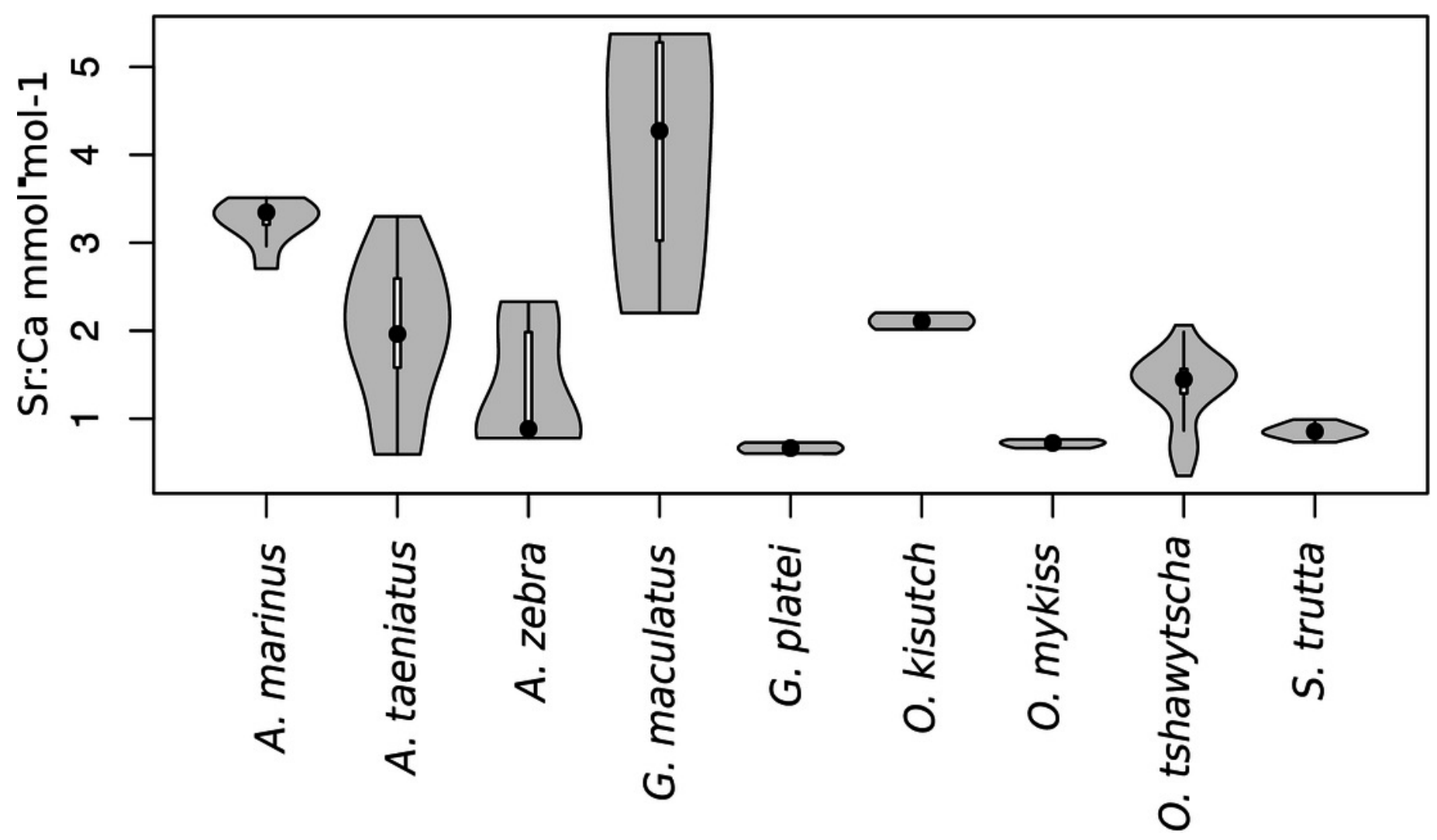




\section{Figure 4 (on next page)}

Detection of discontinuities by semi-supervised CART employed on Sr:Ca ratios for representative individuals of native and exotic fishes in southern Chile.

Numbers after taxonomic names refer to the individual ID of each fish. The mean for each cluster is represented by a continuous black line delimited by a grey box as standard deviation. Vertical dashed lines indicate splitting points induced by the condition used to fit the regression trees, which is reported for each individual graph as "cond" 


\section{Figure 5}

\section{Total number of splits obtained by semisupervised CART on univariate Sr:Ca otolith data for all the species included in the study.}

Frequency of the total number of splits obtained with different conditions (Cond) by semisupervised CART on univariate $\mathrm{Sr}: \mathrm{Ca}$ otolith data for all the species included in the study. Original data for native $A$. taeniatus, $A$. marinus, and $G$. maculatus and introduced $O$. tshawytscha was divided in more than one homogenous cluster by semisupervised regression trees and led to rejection of the hypothesis of freshwater residency. Details for each individual and split reported in this graph are available in the supplementary material Table S2. "Trans" refers to the quality of the otolith transect, that is: "F" is a full or good quality transect, edge core - edge, " $\mathrm{H}$ " is a half transect, edge - core; " $\mathrm{P}$ " is a partial transect, edge - core - extra data without reaching the next otolith edge; " $O$ " is a flagged transect which failed to go through the core and may have some missing data. "St" refers to each fish's ontogenetic phase at the time of capture, where "J" is for juveniles and "A" for adult specimens; "Loc" indicates the sampling locality where AC: Aysén-Caro, CT: Chiloé-Tocoihue, VS: Valdivia-Santo Domingo, VL: Valdivia-Lingue, AP: Aysén-Palos, BE: Baker-estuary, AN: Aysén-Ñireguao, BJ: Baker-Jaramillo, PP: Petrohué-Patos, TP: Toltén-Peuco, TT: Toltén-Truful, AS: AysénSimpson, BV: Baker-Vargas; "Id" is the unique identification of each fish 


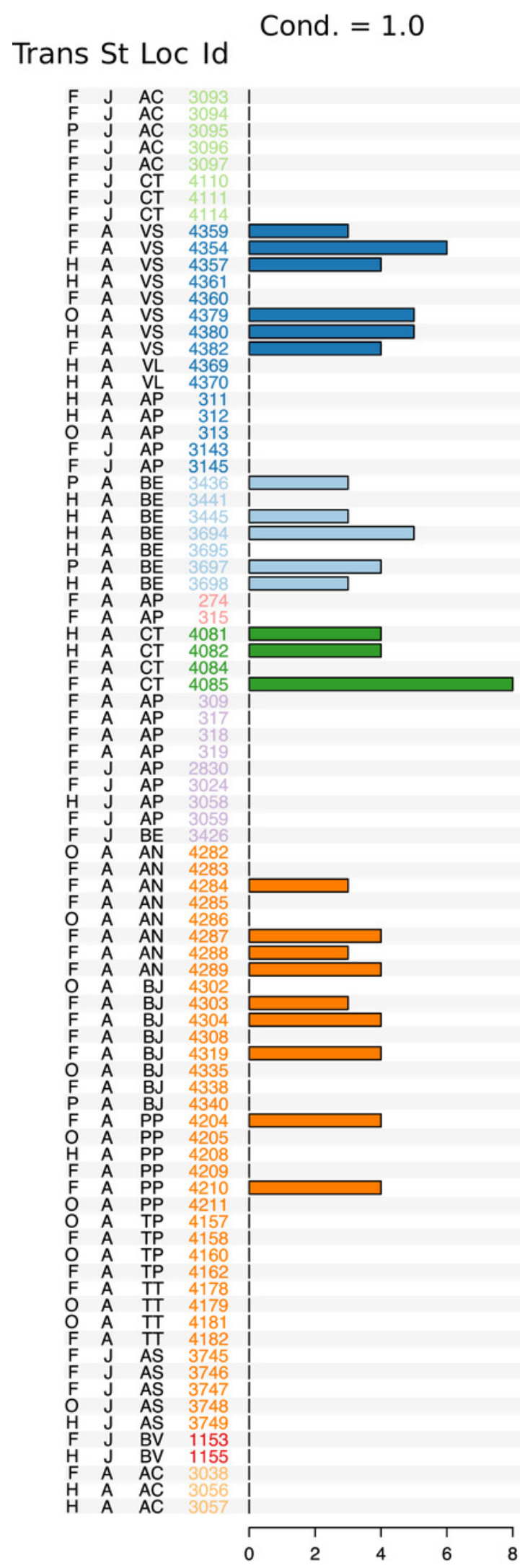

\author{
Cond. $=0.7$ \\ Cond. $=0.5$
}
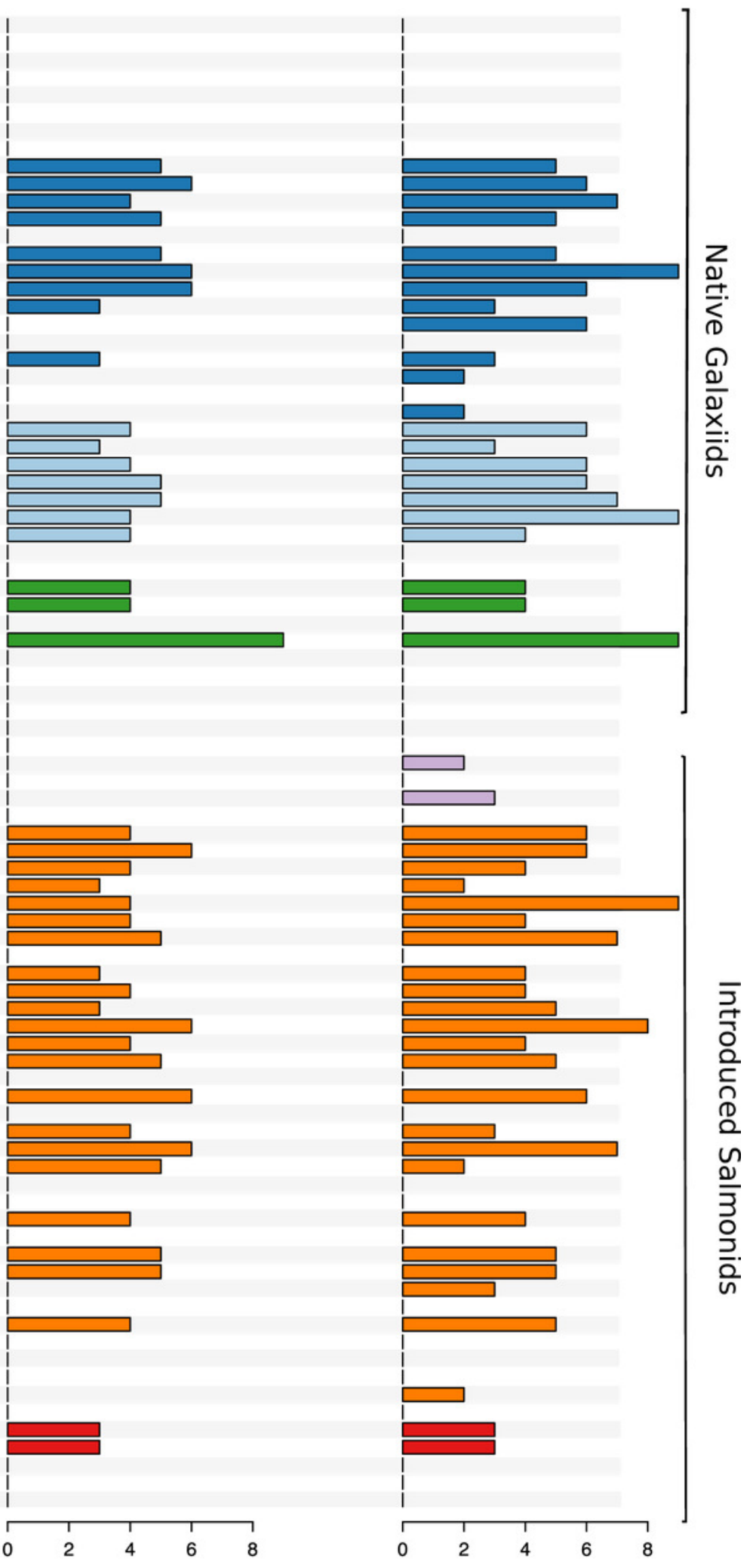

Number of Splits
A. marinus
A. zebra
G. platei
O. mykiss
S. trutta
A. taeniatus
G. maculatus
O. kisutch
O. tshawytscha 


\section{Table $\mathbf{1}$ (on next page)}

Description of the samples studied and summary of results of migration pattern determination.

Values correspond to the percentage of individuals assigned to one of five possible patterns: freshwater resident (FW), brackish water resident (B), anadromous (ANA), catadromous (CAT), amphidromous (AMPH) or else omitted from interpretation due to uncertainties in the otolith transects (O). For individual results, see Table S2 


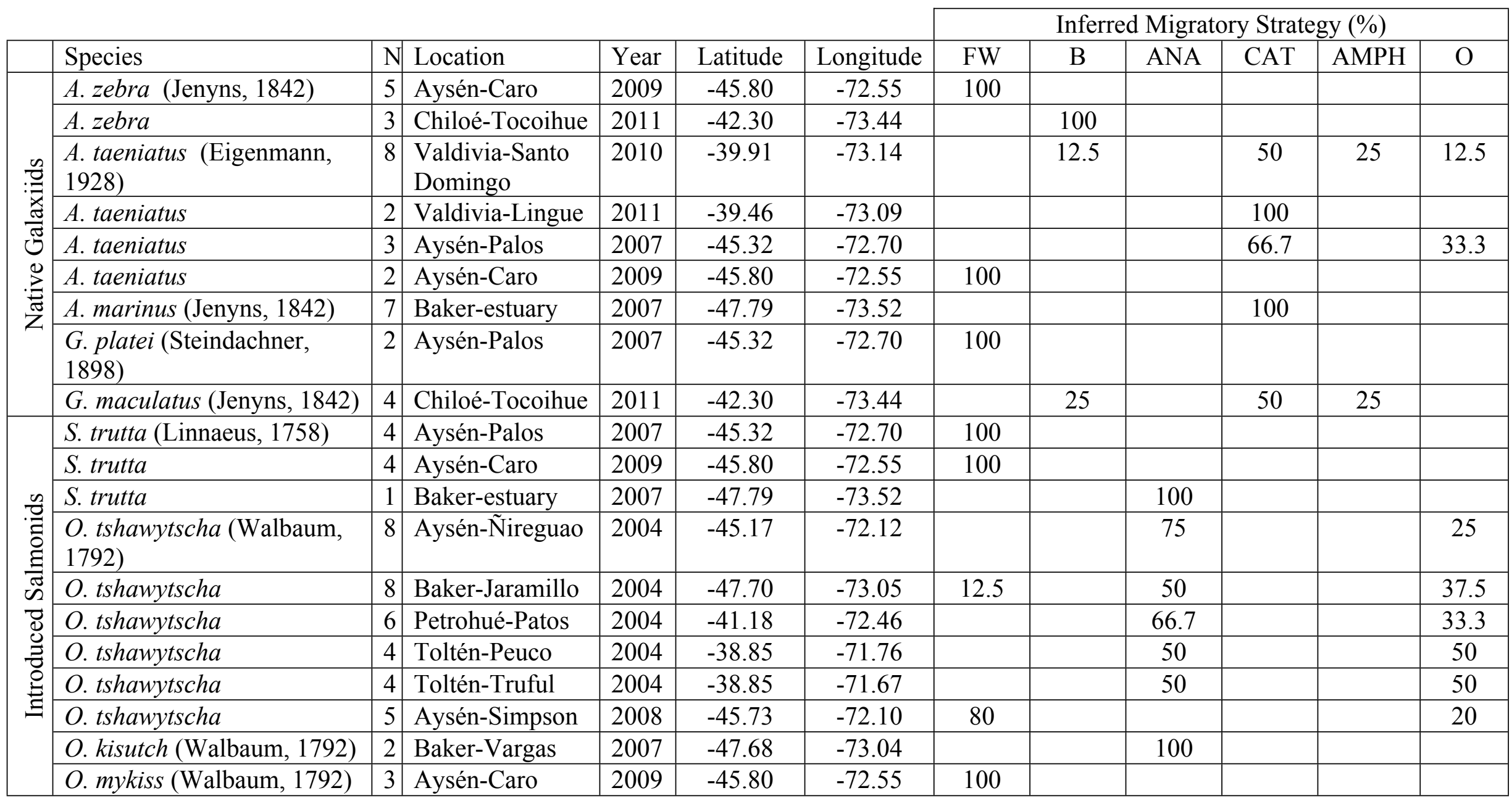

2 